\title{
AIR TEMPERATURE AND THERMAL COMFORT CONDITIONS IN MOUNTAINOUS AND URBAN REGIONS
}

\author{
A. MATSOUKIS, A. KAMOUTSIS \& A. CHRONOPOULOU-SERELI \\ Department of General Sciences, Agricultural University of Athens, Greece
}

\begin{abstract}
The present study explored air temperature and thermal comfort conditions in mountainous region of Nafpaktia (Municipality of Apodotia, Prefecture of Aitoloakarnania), a region without important commercial, industrial or other activities in west continental Greece, and in Athens, a metropolitan urban center in southeast continental Greece. There were 11 study sites in the case of Nafpaktia (676-1455 m altitude), areas with different altitude, ground cover, plant species and plant density. There was one study site in Athens (30 m altitude) nearby a densely built area, under the pressure of industrial activities and heavy traffic. Air temperature and humidity, $1.5 \mathrm{~m}$ above ground surface, were monitored simultaneously every $15 \mathrm{~min}$ in each site for the period between 1 July and 31 August 2006. Air temperature and relative humidity data were used for the calculation of the thermohygrometric index (THI) from which thermal comfort conditions were evaluated. For this work, two sites of mountainous Nafpaktia region (MNR), one characterized by the lower (fir and chestnut forest area) and the other by the higher (Evinos River area) average THI value, are presented. Results showed that MNR provided clearly improved air temperature and thermal comfort conditions in comparison to Athens in the study period. Fir and chestnut forest area was more beneficial, from a bioclimatological point of view, compared to Evinos River area. Therefore, fir and chestnut forest area should be further supported as a reliable alternative tourist destination for rest and recreation.
\end{abstract}

Keywords: Athens, mountainous Nafpaktia, temperature, thermohygrometric index.

\section{INTRODUCTION}

Human activities are directly influenced by air temperature near the ground. Its increase above a limit may deteriorate thermal comfort conditions in the warm season of the year. Thermal comfort is defined as the condition of mind that expresses satisfaction with the thermal environment, absence of thermal discomfort or conditions in which $80 \%$ or $90 \%$ of humans do not express dissatisfaction [1]. Human thermal comfort or discomfort conditions may be determined by a large number of theoretical and empirical indices requesting a larger or smaller number of various parameters [2] such as air temperature, radiation, humidity, clothing, etc. One easily applied index, requiring only air temperature and relative humidity, is the thermohygrometric index (THI) which has been used in urban, rural and urban forest areas. According to THI, the optimum comfort occurs between $15.0^{\circ} \mathrm{C}$ and $19.9^{\circ} \mathrm{C}[3]$.

Urbanization is a common phenomenon in many cities all around the world with a remarkable impact on local climate, attributed merely to construction, industry, traffic and air pollution [2]. Climate modification through urbanization influenced negatively public health in summer [4].

Mountainous forest regions, in general, appear to be more suitable for residents and tourists, contrary to urban areas. The benefits of mountainous forests, from a biometeorological point of view, can be attributed both to their natural environment [5] and to the presence of relatively less human activities. Plants through transpiration release water vapor to the surroundings, increasing humidity [6] and decreasing temperature [7]. Therefore, mountainous forest regions are characterized by more favorable environmental conditions compared to urban regions in the warm months of the year.

Mountainous Nafpaktia is an almost unexploited region with physical beauties such as evergreen forests which may attract people for summer vacations. The only study on the bioclimatological condition of region using THI has been reported by Matsoukis et al. [5]. The aim of this work is to 
evaluate air temperature and thermal comfort conditions in the mountainous Nafpaktia region (MNR) by comparing it to an urban center (Athens) using THI in the warm season of the year.

\section{MATERIALS AND METHODS}

Research for air temperature and thermal comfort conditions was carried out at two regions. The first one was Athens (capital of Greece), a highly populated urban region in southeast continental Greece. The study site, s1 $\left(37^{\circ} 59^{\prime} \mathrm{N}, 23^{\circ} 42^{\prime} \mathrm{E}\right)$, in Athens was located at $30 \mathrm{~m}$ altitude. Nearby area is densely built and is under the pressure of industrial activities and heavy traffic, thus it is a case study of an urban center. Contrary to the first region, the second one is located on a wide part of mountainous Nafpaktia (Fig. 1) districts (Municipality of Apodotia, Prefecture of Aitoloakarnania) in west continental Greece. In this region, unimportant commercial, industrial or other human activities are performed. Its physical beauties, mainly due to fir (Abies sp.) forests, diverse relief and Evinos River indicate noticeable tourist potential. Eleven study sites in MNR were selected (676-1455 m altitude). Selection was mainly based on different altitude, ground cover, plant species and plant density.

Air temperature and humidity, $1.5 \mathrm{~m}$ above ground surface, were monitored simultaneously every 15 min by sensors with data loggers (Hobo type Pro, H-032-08, accuracy $\pm 0.2^{\circ} \mathrm{C}$ at $25^{\circ} \mathrm{C}$ and $\pm 3 \%$ relative humidity over $0-50^{\circ} \mathrm{C}$ ), one for each site in MNR, for the period between 1 July and 31 August 2006. The data loggers were enclosed in appropriate shelters screened from rainfall and direct solar radiation. The form of the shelters allowed acceptable air ventilation. In case of Athens, air temperature and humidity data, during the same period, were provided by the automatic meteorological station of Agricultural University of Athens (Delta-T Devices Ltd, UK).

The mean values of average, maximum and minimum temperatures in Athens were $28.0^{\circ} \mathrm{C}$, $33.3^{\circ} \mathrm{C}$ and $22.0^{\circ} \mathrm{C}$, respectively (meteorological station of Agricultural University, Athens), during the period of hottest months (July-August) from 1991 to 2006. The respective values of the previous parameters were $24.7^{\circ} \mathrm{C}, 31.0^{\circ} \mathrm{C}$ and $16.4^{\circ} \mathrm{C}$ from the nearby meteorological station (Lidoriki, $38^{\circ} 31^{\prime} \mathrm{N}, 22^{\circ} 08^{\prime} \mathrm{E}$, altitude $600.0 \mathrm{~m}$ ) to MNR (distance $25.0 \mathrm{Km}$ ), for the same period from 1975 to 1995 . The mean values of average and extreme temperatures were higher in Athens compared to Lidoriki.

For air temperature and relative humidity data, means on hourly basis were calculated for each study site. These means were used for the calculation of the average and hourly values of THI, a

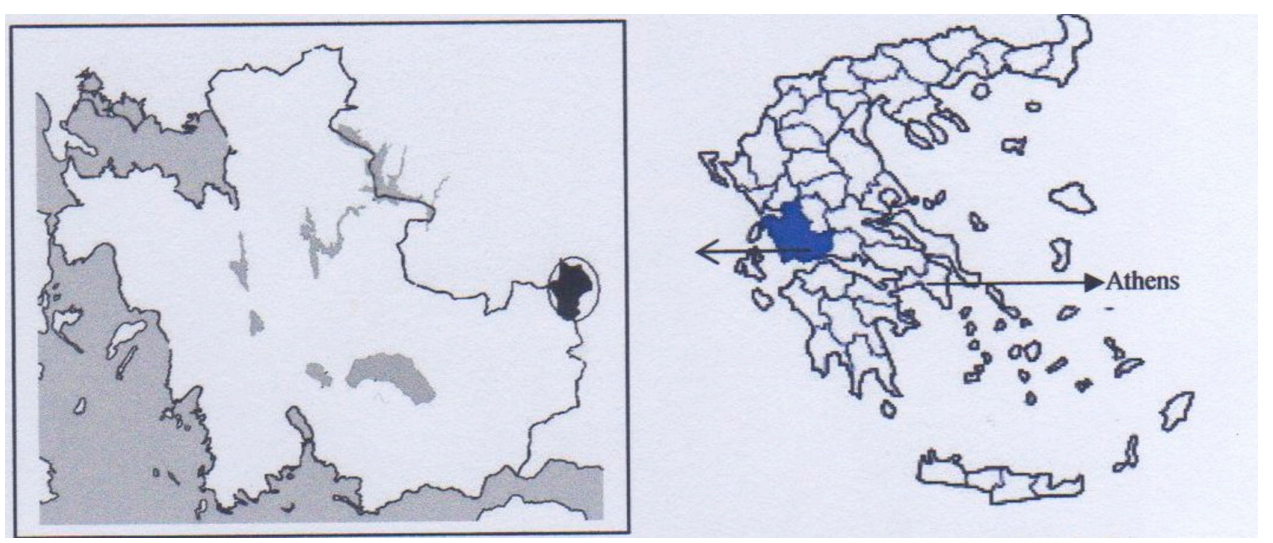

Figure 1: Mountainous Nafpaktia region (with black color inside the circle). 
widely used biometeorological index [3], for the whole experimental period. THI value was used for the evaluation of human thermal comfort category according to Unger [2]. Five categories of thermal comfort (very hot, hot, comfortable, cool and cold) were detected. Also, the relative frequencies of different categories of the index mentioned above were calculated on hourly basis for the examined period. Of all the sites, studied in Nafpaktia, only two sites of MNR, the first of which was characterized by the higher and the second by the lower average THI values, are presented for this work. The first site, s2 $\left(38^{\circ} 43^{\prime} \mathrm{N}, 21^{\circ} 57^{\prime} \mathrm{E}\right)$, was located at $676 \mathrm{~m}$ altitude, by the Evinos River, among various riverside plant species and the second, $\mathrm{s} 3\left(38^{\circ} 43^{\prime} \mathrm{N}, 22^{\circ} 01^{\prime} \mathrm{E}\right)$, was located at $986 \mathrm{~m}$ altitude, inside a forest with firs and chestnut trees (Castanea sp.). Analysis was performed using MS Excel and SPSS v.11.0 statistical program.

\section{RESULTS}

The mean values of average and extreme (maximum, minimum) temperatures at s1 site in Athens and at other two sites (s2, s3) in MNR are shown in Fig. 2. Average and extreme temperatures were higher in Athens compared to MNR. More specifically, the average temperature decreased by $7.0^{\circ} \mathrm{C}$ and $8.3^{\circ} \mathrm{C}$ in the sites s2 (elevation difference from Athens $646.0 \mathrm{~m}$ ) and s3 (elevation difference from Athens $956.0 \mathrm{~m}$ ), respectively, compared to Athens. Fir and chestnut forest area (s3) was cooler by $1.3^{\circ} \mathrm{C}$ compared to Evinos River area (s2).

The mean maximum temperature was lower by $2.9^{\circ} \mathrm{C}$ and $6.0^{\circ} \mathrm{C}$ at the sites s2 and s3, respectively, compared to $\mathrm{s} 1$ site during the examined period. The decrease of minimum temperature in the Evinos River area (s2) compared to Athens (s1) was higher than the respective decrease in the fir and chestnut forest area (s3). Minimum temperature in the fir and chestnut forest area was higher by $1.7^{\circ} \mathrm{C}$ compared to Evinos River area.

Table 1 shows the calculated average and extreme THI values according to hourly means of air temperature and relative humidity data for the whole experimental period. It can be seen that average

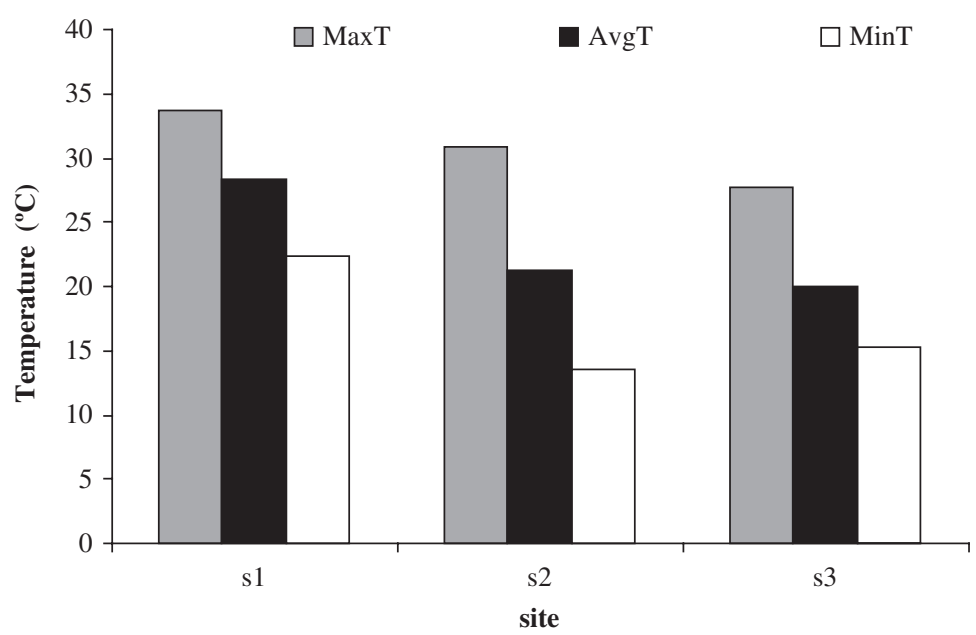

Figure 2: Air temperature conditions in the urban region of Athens (s1), in the Evinos River area (s2) and in the fir and chestnut forest area (s3) of MNR during the period July-August 2006. MaxT, maximum air temperature; AvgT, average air temperature; MinT, minimum air temperature. 
Table 1: Average, maximum and minimum THI values of the study sites.

\begin{tabular}{lccc}
\hline Sites & Average THI $\left({ }^{\circ} \mathrm{C}\right)$ & Maximum THI $\left({ }^{\circ} \mathrm{C}\right)$ & Minimum THI $\left({ }^{\circ} \mathrm{C}\right)$ \\
\hline Athens & 23.87 & 29.78 & 17.42 \\
Evinos River area & 19.12 & 28.51 & 9.79 \\
Fir and chestnut forest area & 18.42 & 26.39 & 10.88 \\
\hline
\end{tabular}

THI category is 'hot' in the urban region of Athens (s1), while those of both presented sites (s2 and s3) in Nafpaktia are 'comfortable'. In terms of maximum THI values, Athens (s1) and Evinos River area (s2) are in 'very hot' category, while the fir and chestnut forest area (s3) is in 'hot' category. With regard to minimum THI values, s2 and s3 sites are in the 'cold' category, while Athens is in 'comfortable' category [2].

Thermal comfort conditions as expressed by the relative frequencies of different categories of THI values in each hour for the examined period at the two sites (s2, s3) of MNR and in Athens (s1) are presented in Fig. 3. Three THI categories in Athens (very hot, hot and comfortable) and five categories (very hot, hot, comfortable, cool and cold) in MNR were detected. Relative frequencies were analyzed in average terms. More specifically, from 09:00 to 20:00, 24.6\% of the THI values were in the 'very hot' category and the rest (75.4\%) were in the 'hot' category in Athens (Fig. 3a).

For the same period, it was found that the majority of THI values (78.0\%) were in the 'hot' category, while $18.5 \%$ and $2.7 \%$ were in the 'comfortable' and 'very hot' categories, respectively, in the Evinos River area (Fig. 3b). In the fir and chestnut forest area (s3), 55.9\% of the THI values were in the 'hot category' (Fig. 3c) and a considerable percentage (40.1\%) was in the 'comfortable' category. A very small percentage of the THI values were in the 'cool' (2.8\%) and 'cold' (1.2\%) categories (Fig. 3c).

At night and morning hours (from 21:00 to 08:00), the majority (92.7\%) and a small percentage $(7.0 \%)$ of THI values were in the 'hot' and 'comfortable' categories, respectively, in Athens (Fig. 3a). In the Evinos River (s2) and the fir and chestnut forest (s3) areas, 53.9\% and $67.5 \%$ of THI values were in the 'comfortable' category during the above period, respectively (Fig. $3 \mathrm{~b}$ and c). In addition, in the Evinos River area, a considerably large percentage of THI values were in the 'cool' and 'cold' categories (28.4\% and $10.6 \%$, respectively). In the case of fir and chestnut forest area (Fig. 3c), it was seen that THI values were in the 'cool' and 'cold' categories with $19.6 \%$ and 5.4\%, respectively, from 21:00 to 8:00. Additionally, it was found that 7.5\% of THI values were in the 'hot' category in the fir and chestnut forest area. It is noticeable that there was an absence of the 'very hot' category in fir and chestnut forest area during the whole examined period (Fig. 3c).

\section{DISCUSSION}

From the results of the study, it can clearly be seen that the mountainous region of Nafpaktia is bioclimatologically more advantageous than Athens when both air temperature and thermal comfort conditions for the whole examined period were considered. This may be attributed to lower average and extreme temperatures combining with the most frequent occurrence of 'comfortable' category in MNR compared to Athens. Although Athens (s1) is too away from MNR (s2 and s3) and this distance may be effective on the differences in temperature and thermal comfort conditions, this study is important for, at least, it can give an idea about the thermal comfort condition alterations in mountainous and urban areas. The temperature and thermal comfort differentiation, in general, between MNR and Athens could be explained merely by the altitude, the presence of vegetation and the water surface in MNR in a higher degree, compared to Athens. Because of the most frequent occurrence of 'hot' category in Athens, attributed mainly to urbanization [5], people must defend 
(a)
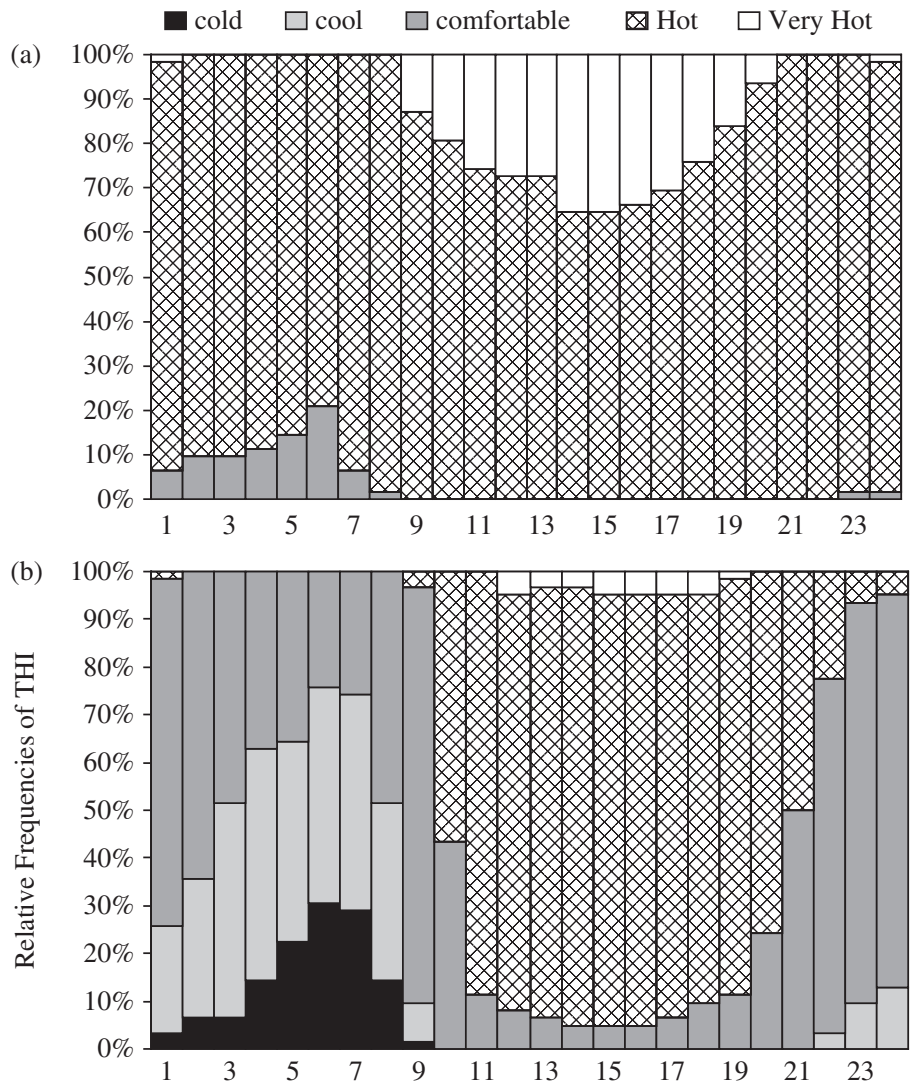

(c)

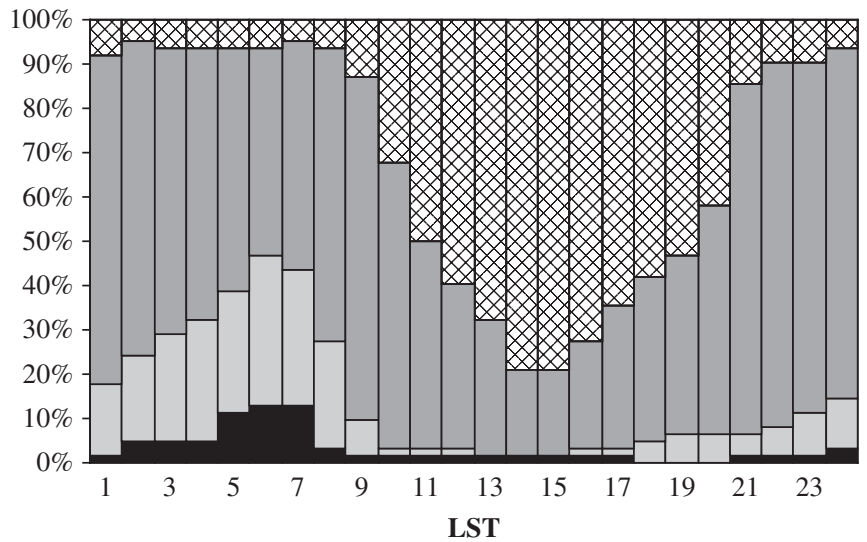

Figure 3: Relative frequencies of different categories of THI values on hourly basis in Athens (a), the Evinos River area (b) and the fir and chestnut forest area (c) of MNR during the period of July-August 2006 (local standard time (LST) = Greenwich Meridian Time +2 h). 
themselves against heat stress in the examined period. MNR provides an additional advantage against heat stress because of the 'shading effect of the trees' [3], especially in the fir and chestnut forest area, and because of the high altitude.

In the mountains, the plant density and height in combination with topography parameters, such as the altitude and the aspect, determine the mosaic of topoclimates and microclimates of different areas [8]. The fir and chestnut forest area was more beneficial due to the more frequent percentage of THI values in 'comfortable' category compared to Evinos River area. The density of vegetation was lower in previous area, that is to say 'open area' in many sites, compared to fir and chestnut forest area. The lower average and maximum temperature in fir and chestnut forest area compared to Evinos River area could be explained by the fact that solar radiation and temperature (at least on sunny days) are lower in forest compared to open sites, near the ground [9].

The lower minimum temperature and the greater percentage of THI values in 'cool' and 'cold' categories at the Evinos River area, compared to fir and chestnut forest area during night and morning hours (21:00-08:00), could be attributed to the movement of cold air, formed by nocturnal radiative cooling under calm clear sky conditions $[8,10]$, from elevated areas towards the lower altitudes. Evinos River area, as already mentioned, is at lower altitude compared to fir and chestnut forest area (elevation difference $310.0 \mathrm{~m}$ ).

In MNR, bioclimatologically, the more advantageous area is fir and chestnut forest area, for that reason this area could be introduced as a reliable alternative tourist destination, by preserving the natural vegetation and the traditional character of the region.

\section{ACKNOWLEDGEMENTS}

This research is a part of the project co-funded by European Social Fund \& National Resources Operational Programme for Education and Initial Vocational Training (EPEAEK II), 'Environment-Pythagoras II-Funding of Research Groups in Agricultural University of Athens'.

\section{REFERENCES}

[1] Yilmaz, S., Toy, S. \& Yilmaz, H., Human thermal comfort over three different land surfaces during summer in the city of Erzurum, Turkey. Atmósfera, 20(3), pp. 289-297, 2007.

[2] Unger, J., Comparisons of urban and rural bioclimatological conditions in the case of a Central-European city. International Journal of Biometeorology, 43, pp. 139-144, 1999. doi:10.1007/s004840050129

[3] Toy, S., Yilmaz, S. \& Yilmaz, H., Determination of bioclimatic comfort in three different land uses in the city of Erzurum, Turkey. Building and Environment, 42, pp. 1315-1318, 2007. doi:10.1016/j.buildenv.2005.10.031

[4] Clarke, J.F. \& Bach, W., Comparison of the comfort conditions in different urban and suburban microenvironments. International Journal of Biometeorology, 15, pp. 41-54, 1971. doi:10.1007/BF01804717

[5] Matsoukis, A., Kamoutsis, A., Charalampopoulos, I., Panagiotou, I. \& Chronopoulou-Sereli, A., Evaluation of biometeorological conditions of mountain communities and urban center in Greece. Proc. of Secotox Conf. and the Int. Conf. on Environmental Management, Engineering, Planning and Economics, eds A. Kungolos, K. Aravossis, A. Karagiannidis \& P. Samaras, Grafima Publications: Skiathos, pp. 1526-1530, 2007.

[6] Jones,H.G.,Plants andmicroclimate:A quantitative approach to environmentalplantphysiology, 2nd edn, Cambridge University Press: Cambridge, London and New York, pp. 120-124, 1992. 
[7] Gates, D.M., Plant temperatures and energy budget (Chapter I). Temperature and life, eds H. Precht, J. Christophersen, H. Hensel \& W. Larcher, Springer-Verlag: Berlin, Heidelberg and New York, pp. 87-101, 1973.

[8] Barry, L.G., Mountain Weather and Climate, 2nd edn, Routledge, Taylor and Francis Group: New York, pp. 18-189, 2001.

[9] Morecroft, M.D., Taylor, M.E. \& Oliver, H.R., Air and soil microclimates of deciduous woodland compared to an open site. Agricultural and Forest Meteorology, 90, pp. 141-156, 1998. doi:10.1016/S0168-1923(97)00070-1

[10] Oke, T.R., Boundary Layer Climates, 2nd edn, Routledge, Taylor and Francis Group: New York, pp. 176-181, 1999. 